\title{
Diagnosis and outcome measures in trials for neoplastic meningitis: a review of the literature and clinical experience
}

\section{Michael J. Glantz, M.D., Marc C. Chamberlin, M.D., and Beverly C. Walters, M.D., M.Sc.}

University of Massachusetts School of Public Health, Amherst, Massachusetts; University of California at San Diego, San Diego, California; and Brown University School of Medicine, Providence, Rhode Island

Innovative approaches to the treatment of neoplastic meningitis are being widely tested. Unfortunately, research on diagnostic strategies and outcome measures on which any advances in treatment ultimately depend, has not been avidly pursued.

A critical review of the literature on neoplastic meningitis published since 1978 was undertaken by using MEDLINE and other English language databases. All articles addressing the issues of diagnostic or response criteria were included. Randomized clinical trials (RCTs) were emphasized. Prospectively collected data from the authors' institution correlating the results of cerebrospinal fluid (CSF) cytological examinations with Karnofsky Performance Scale (KPS) score are also discussed.

Twenty-six studies (representing 1208 patients) fulfilled search criteria. Only three were RCTs. Cerebrospinal fluid cytology was the sole diagnostic criterion in two-thirds of studies. The results of CSF cytological examination alone or in combination with other clinical or laboratory endpoints constituted the primary outcome measure in $85 \%$. Few studies attempted to address known deficiencies in the reliability and validity of these measures, and correlation between measures was poor. Quality of life was never used as a primary outcome measure.

All currently available measurements, including CSF cytology, biochemistry, immunological, and molecular markers, neuroimaging studies, clinical examination, and survival, suffer from poor sensitivity and/or specificity, and often correlate poorly with each other. Although CSF cytological examination, performed according to a rigorous, research-supported protocol, may be the optimum diagnostic and outcome measure at this time, additional research is a prerequisite for any further advances in the clinical care of patients with neoplastic meningitis.

Key Words * neoplastic meningitis * outcome measure * cerebrospinal fluid * cytology * diagnosis

The first pathological description of neoplastic meningitis was published 130 years ago,[20] and nearly a century ago, Saenger[62] provided the first clinical description of this disease. In 1904, Dufour[51] first identified malignant cells in the cerebrospinal fluid (CSF). The first two of these events now hold our interest only as historical landmarks. The third study, however, describes a laboratory procedure that remains the gold standard for diagnosing neoplastic meningitis and evaluating the outcome of therapeutic interventions.[22,25,32,37,57,74]

Despite increasing interest and an increasing frequency of the disease, $[39,42,74,76]$ important innovations in disease staging, $[10,13,34,41,42]$ and promising new therapeutic approaches,[6,33,36] neoplastic meningitis continues to be defined by the detection of malignant cells in the CSF, and novel treatments continue to be evaluated based on their ability to convert a positive CSF cytological examination to a negative one. The purpose of this study is to review the diagnostic and response criteria that have been applied in clinical trials of treatment for 
solid tumor neoplastic meningitis over the last 20 years. Cerebrospinal fluid cytological examination is emphasized because of its pivotal role, but other diagnostic and outcome measures including biochemical markers, neuroimaging studies, clinical examination, and functional measures, are also discussed. From this review, recommendations for current practice are made.

\section{CLINICAL MATERIAL AND METHODS}

\section{Review of Literature}

This study has two purposes: the first is an attempt to thoroughly review the literature on neoplastic meningitis to establish the context of current practice. For this, all observational and analytical clinical trials of treatment for neoplastic meningitis published in English since 1978, that primarily focused on outcome rather than prognostic factors, and that provided sufficient data to determine the diagnostic and outcome measures used, were reviewed. Pertinent studies were identified by using MEDLINE searches of the years 1978 through April of 1998. Additional studies were obtained by review of the reference lists of these articles, and of abstracts appearing in the abstract books of the American Society of Clinical Oncology and American Association of Neurology since 1992.

\section{Karnofsky Performance Scale Scores and CSF Cytology}

The second purpose is to report our own experience comparing Karnofsky Performance Scale (KPS) scores with the results of CSF cytological examination in 30 patients known to have neoplastic meningitis. These patients were participants in institutional review board-approved clinical trials conducted by the Neuro-Oncology Service at the Brown University School of Medicine from 1992 through 1995.

\section{RESULTS}

Since 1978, 26 studies comprising 1247 patients were identified that provided information on diagnostic and response criteria in patients with solid tumor neoplastic meningitis. $[4,5,11,14,18,21,23,29,31,33,36,38,40,42,46,53,56,61,63,66,67,69,70,74-76]$ Only three of these studies (with a total of 154 patients) were randomized clinical trials, [36,40,42] and one of these has, as yet, been published only in abstract form. The remainder are phase I or phase II trials (9), case control studies (3), or case series (11).

\section{Diagnostic Criteria}

Of the 26 studies, 16 (62\%), including two of the three randomized clinical trials, relied solely on a positive CSF cytology as the diagnostic entry criterion. $[4,5,11,18,31-33,38,40,46,56,63,66,69,75,76]$ One additional study required both positive CSF cytology and the presence of multifocal neurological deficits compatible with the diagnosis of neoplastic meningitis.[53] In the remaining nine studies (35\%)[21,23,29,39,42,61,67,70,74] abnormalities of CSF biochemistry or cell count, clinical examination, or neuroimaging studies (myelography, computerized tomography, or magnetic resonance [MR] imaging), alone or in various combinations, were accepted in some patients as sufficient evidence of neoplastic meningitis in the absence of a positive CSF cytology (Table 1). 


\begin{tabular}{|c|c|c|c|c|c|c|c|c|}
\hline \multirow[b]{2}{*}{ Authors and Year } & \multicolumn{4}{|c|}{ Diagnostic Criteria } & \multicolumn{4}{|c|}{ Outcome Measures } \\
\hline & $\begin{array}{l}\text { No. } \\
\text { of Pa- } \\
\text { tients }\end{array}$ & $\begin{array}{l}\text { Cy- } \\
\text { tology } \\
\text { Alone }\end{array}$ & $\begin{array}{l}\text { Additional } \\
\text { Study } \\
\text { Entry Criteria }\end{array}$ & $\begin{array}{l}\text { Cytology } \\
\text { Not Used }\end{array}$ & $\begin{array}{l}\text { No. } \\
\text { of Pa- } \\
\text { tients }\end{array}$ & $\begin{array}{l}\mathrm{Cy} \\
\text { tology } \\
\text { Alone }\end{array}$ & $\begin{array}{c}\text { Additional } \\
\text { Study Re- } \\
\text { sponse Criteria }\end{array}$ & $\begin{array}{l}\text { Cytology } \\
\text { Not Used }\end{array}$ \\
\hline Yap, et al., 1978 & 25 & 25 & & & 25 & cytology & & \\
\hline Edmards, et al., 1981 & & 13 & & $\begin{array}{l}\text { positi ve CSF } \\
\text { cytology \& } \\
\text { characteristic } \\
\text { m yelogram }\end{array}$ & 13 & & $\begin{array}{l}\text { + CSF chem } \\
\text { + exam }\end{array}$ & \\
\hline $\begin{array}{l}\text { Theodore \& } \\
\text { Gendelm an, } 1981\end{array}$ & 33 & 33 & & & 33 & & + exam & \\
\hline Fulton, et al., 1982 & 32 & 16 & & $\begin{array}{l}\text { CT or m yelo- } \\
\text { graphy' }\end{array}$ & 32 & & + exam & \\
\hline $\begin{array}{l}\text { Rosen, et al., } 1982 \\
\text { Trum p, et al., } 1982\end{array}$ & $\begin{array}{l}60 \\
25\end{array}$ & $\begin{array}{l}37 \\
23\end{array}$ & $\begin{array}{l}2 \text { CSF chem, } \\
\text { xtay, exam }\end{array}$ & 23 at auto psy & $\begin{array}{l}60 \\
25\end{array}$ & & $\begin{array}{l}\text { + exam } \\
\text { + exam }\end{array}$ & \\
\hline $\begin{array}{l}\text { 'idasserstrom, et al., } \\
1982\end{array}$ & 90 & 82 & & $\underset{\text { xtay }}{8 \text { exams }+}$ & 90 & & + exam & \\
\hline Yap, et al., 1982 & 40 & 40 & & & 39 & & $\begin{array}{l}+ \text { CSF chem } \\
\text { + exam }\end{array}$ & \\
\hline $\begin{array}{l}\text { de Visser, et al., } 1983 \\
\text { Giannone, et al } 1986\end{array}$ & 33 & 33 & & & 33 & & + exam & \\
\hline $\begin{array}{l}\text { Glannone, et al. } 1960 \\
\text { Hitchins, et al., } 1987\end{array}$ & 44 & 33 & 11 CSF chem, & & 41 & & $\begin{array}{l}\text { + exam } \\
\text { + exam }\end{array}$ & \\
\hline Ste mart, et al., 1987 & 23 & 17 & & $\begin{array}{c}5 \text { exams }+ \\
x+a y\end{array}$ & 22 & & $\begin{array}{l}\text { + CSF chem } \\
\text { + exam }\end{array}$ & \\
\hline Pfeffer, et al., 1988 & 98 & 98 & & & 71 & & + exam & \\
\hline $\begin{array}{l}\text { Sause, et al., } 1988 \\
\text { Boogerd, et al. } 1991\end{array}$ & $\begin{array}{l}27 \\
44\end{array}$ & $\begin{array}{l}27 \\
44\end{array}$ & & & $\begin{array}{l}26 \\
31\end{array}$ & & $\begin{array}{l}\text { + exam } \\
\text { + exam }\end{array}$ & \\
\hline Berg, et al., 1992 & 39 & 39 & & & 39 & $\begin{array}{l}\text { cytology } \\
\text { alone }\end{array}$ & & \\
\hline $\begin{array}{l}\text { Nakagama, et al. } \\
1992\end{array}$ & 34 & 34 & $\begin{array}{l}+ \text { multifocal neu- } \\
\text { rological deficits }\end{array}$ & & 34 & & & $\begin{array}{l}\text { survival } \\
\text { only }\end{array}$ \\
\hline $\begin{array}{l}\text { Grossm an, et al., } \\
1993\end{array}$ & 52 & 52 & & & 52 & & $\begin{array}{l}+ \text { exam } \\
+x \text {-ray }\end{array}$ & \\
\hline Grant, et al., 1994 & 36 & 36 & & & 36 & & & $\begin{array}{l}\text { survival } \\
\text { only }\end{array}$ \\
\hline Jayson, et al., 1994 & 35 & 35 & & & 35 & & & $\begin{array}{l}\text { exam } \\
\text { only }\end{array}$ \\
\hline Siegal, et al., 1994 & 137 & 137 & & & 137 & & + exam & \\
\hline $\begin{array}{l}\text { Balm \& Hamm ack, } \\
1996\end{array}$ & 126 & 126 & & & 126 & & & $\begin{array}{l}\text { exam } \\
\text { only }\end{array}$ \\
\hline Fizazi, et al., 1996 & 68 & 61 & $\begin{array}{l}7 \text { CSF protein + } \\
\text { CT }\end{array}$ & & 62 & & + exam & \\
\hline $\begin{array}{l}\text { Glant, et al., } 1996 \\
\text { Glant, et al., } 1998\end{array}$ & $\begin{array}{l}61 \\
31\end{array}$ & $\begin{array}{l}61 \\
31\end{array}$ & & & $\begin{array}{l}60 \\
31\end{array}$ & $\begin{array}{l}\text { cytology \& } \\
\text { exam as- } \\
\text { sessed } \\
\text { separately }\end{array}$ & + exam & \\
\hline $\begin{array}{l}\text { Cham berlin } 8 \\
\text { Kom anik, } 1998\end{array}$ & 32 & 26 & $\begin{array}{l}6 \text { CSF chem, } x- \\
\text { ray exam }\end{array}$ & & 32 & & + exam & $\begin{array}{l}6 \text { exam } \\
+ \text { x-ray }\end{array}$ \\
\hline
\end{tabular}

Despite widespread acceptance of CSF cytology as a diagnostic gold standard for neoplastic meningitis, serious doubts about the validity and reliability of this technique have recently been raised.[4] Whereas false-positive studies are rare or nonexistent in cases of solid tumor neoplastic meningitis, $[2,9,22,37,50,74]$ false-negative results are common, particularly when small CSF volumes $\left(<10.5 \mathrm{~cm}^{3}\right)$ are submitted, when specimens are not processed by the cytology laboratory immediately, when CSF is obtained from a site distant from the location of active CSF disease (that is, from the lumbar region in patients with cranial nerve or cerebral signs and symptoms or from a 
ventricular reservoir in patients with predominantly spinal disease), or when a second CSF specimen is not obtained after an initial specimen is cytologically negative.[32] In addition, inadequate communication between clinician and cytopathologist, as well as inadequacies in cytopreparatory technique, may also contribute substantially to false-negative results. Many of these pitfalls are obvious, and all have been explicitly described, but adherence to strategies for avoiding them in clinical practice is probably quite low.[32,73]

In an attempt to avoid underdiagnosis based on the results of CSF cytological examination alone, many authors have advocated the use of supplementary or alternative diagnostic techniques, including clinical examination, MR imaging;[15,25,68] CSF leukocyte count, glucose and protein studies; assays for tumor markers; $[3,26,45,49,54,64,71,74]$ DNA amplification procedures; $[59,60]$ flow cytometry; $[16,19,52]$ and monoclonal antibody staining.[7,8,43,72] Of these techniques, MR imaging has been the most widely embraced. Some investigators have suggested that a secure diagnosis of neoplastic meningitis can be made based on characteristic MR and clinical findings in the absence of a positive CSF cytological examination.[25,28] Such a claim resonates with many clinicians, who have on occasion encountered cancer patients in whom is found the compelling clinical and radiographic evidence of neoplastic meningitis but a persistently negative CSF cytology. When specific MR criteria have been applied, several studies have demonstrated moderate correlations between the results of cytological examination and MR imaging either in small groups of patients with known neoplastic meningitis[15,68,77] or in larger groups with a clinical suspicion of neoplastic meningitis.[25] Unfortunately, reliance on MR imaging alone is associated with frequent false-negative and false-positive results, and many conditions, some common in cancer patients, have been described that mimic "diagnostic" MR findings.[1,24,48,55,58,65] In our own prospective comparison of the results of CSF cytological examination, MR imaging, and clinical examination in patients with gliomas when the results of CSF cytological examination were used as the reference study, the false-negative and false-positive rates for MR imaging (65\% and 8\%, respectively) and clinical examination ( $48 \%$ and $48 \%$, respectively) were unacceptably high.[44]

A large number of biochemical and molecular markers derived from tumor cells and measurable in the CSF have also been evaluated as diagnostic tools for neoplastic meningitis.[3,26,45,49,54,64,71,74] Whereas some studies have shown good correlation between the presence of malignant cells, as documented by conventional CSF cytological examination, and one or more biochemical markers, no marker or panel of markers has been sensitive and specific enough to gain widespread acceptance. The same can be said for the routine CSF parameters, including leukocyte count, glucose, and protein.[47,49,74] Although neoplastic meningitis produces typical abnormalities in one or more of these parameters in most patients, these changes are very nonspecific. Similarly, whereas polymerase chain reaction and immunohistochemical techniques have proven very useful in classifying malignant cells found in the CSF, they cannot substitute for the diagnosis of neoplastic meningitis by standard cytological procedures.[7,8,43,59,60,72]

\section{Outcome Measures}

In most clinical trials, response determinations, like diagnostic criteria, have depended heavily on the results of CSF cytological examination. Two of the 26 studies reviewed here used these results as the sole outcome measure.[5,75] In one study, CSF cytological and clinical examination were reported separately,[31] and in another study the results of CSF cytological examination was the sole response criterion in 26 of 32 patients with positive cytologies at study entry.[13] Eighteen studies (69\%) combined changes in CSF cytology with the results of clinical examination (14 studies), $[11,18,23,29,31,35,42,56,61,63,69,70,74]$ clinical examination combined with CSF biochemistry (3 studies),[21,67,75] or neuroradiographic studies (1 study),[39] to develop specific formulas for determining response. Four studies used as their sole outcome measure either survival (two studies) $[38,53]$ or clinical examination (two studies). $[4,46]$ In those studies relying partly or wholly on the results of CSF cytological examination as the primary response measure, the definition of cytologic clearing (number of requisite samples, duration of clearing, location of sampling, CSF volume, techniques for CSF examination) varied widely. Some studies included partial as well as complete cytological response categories. Similar variability applied to the criteria used for clinical and radiographic responses in those studies for which these were used. In 24 of the 26 studies, survival was also used as an outcome measure (Table 1). 
The same limitations that affect cytology as a diagnostic measure apply to the use of cytology as a response measure.[32] Several recent studies have correlated cytological response with neurological improvement or overall survival. Fizazi, et al.,[23] reported clinical improvement in 10 (67\%) of 15 cytological responders compared with seven $(27 \%)$ of 26 cytological nonresponders in their study of intrathecal methotrexate; however, the difference between groups diminished when patients who were clinically improved and stable were combined (93\% compared with 65\%). Glantz, et al.,[36] found that a single negative CSF cytology following entry into their randomized clinical trial was strongly predictive of prolonged survival compared with patients who never had negative cytology results (60 days compared with 140 days; $\log$ rank $p$ value $=0.0024$ ). In contrast, others have found no correlation between survival and the results of CSF cytological examination following the onset of treatment.[11,66] Whereas these authors were rigorous in evaluating CSF cytology, inadequate sampling techniques and treatment-induced cytological atypia may explain some instances of poor correlation between the results of CSF cytology and survival in other studies.

A second confounding problem is the frequency of death from causes unrelated to neoplastic meningitis. Because most patients with neoplastic meningitis also have progressive systemic cancer, $[22,35,39,40,42,57]$ it is not surprising that systemic cancer is the primary or a major contributing cause of death in 39 to $88 \%$ (mean $46 \%$ ) of patients.[18,23,36,56,69,74,76] As a result, even well-controlled leptomeningeal cancer, as evidenced by a negative CSF cytology result and stable neurological examination, may not be predictive of prolonged survival. Thus cause of death (neoplastic meningitis compared with systemic cancer) is another endpoint that some investigators have used to evaluate the effect of various treatments. Because treatment, compared with supportive care alone, seems to shift the cause of death substantially from neoplastic meningitis to systemic cancer, an argument can be made for the utility of this outcome measure.[18,56,69] Unfortunately, determination of cause of death in this setting is difficult. No published study has used prospectively defined criteria and blinded raters, and therefore this outcome measure remains inadequately explored.

A similar lack of consistency can be found in attempts to use clinical status (as indicated either by the neurological examination or KPS score) as a measure of successful therapy. Two studies have reported improved survival in patients who responded clinically compared with those without clinical improvement,[46,67] but most investigators have found that neurological deficits present when treatment is initiated rarely improve even if treatment successfully eliminates malignant cells from the CSF and prolongs survival.[38,40,57,74] In our own recent experience in 30 patients with neoplastic meningitis for whom survival times and serial cytological and KPS data were available, three patterns of correlation or noncorrelation between these parameters were seen. In 25 patients (83\%), there was no discernible association between KPS score and the presence of malignant cells in the CSF. In 16 of these 25 patients, the KPS score declined despite persistently negative cytology results (Fig. 1 upper). In nine, the KPS score remained stable despite the continuing presence of malignant cells (Fig. 1 center). Finally, in only five patients (17\%) was there good correlation between the KPS score and CSF cytology results (Fig. 1 lower). 

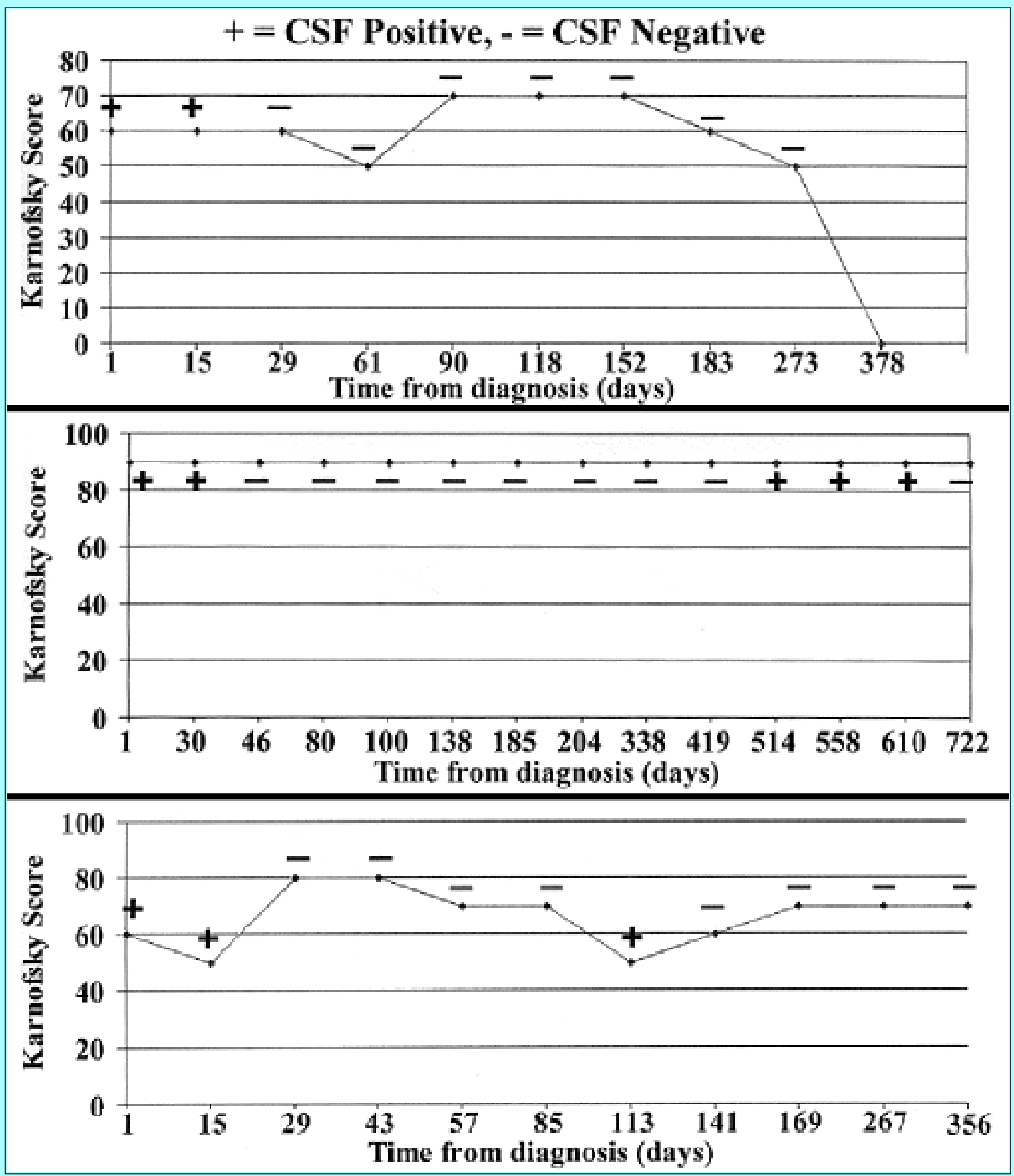

Fig. 1. Graph illustrating the relationship of the results of CSF cytological examination to KPS score. Upper: Plot of CSF cytology results and KPS scores compared with time demonstrating progressive deterioration in KPS score and ultimately death from neoplastic meningitis despite a persistently negative CSF cytology result. Center: Plot of CSF cytology results and KPS scores compared with time demonstrating unwaveringly high KPS score over time and prolonged survival despite reappearance of malignant cells in the CSF. Lower: Plot of CSF cytology results and KPS scores compared with time demonstrating falls in KPS score with reappearance of malignant cells in the CSF and improvement in KPS score with disappearance of malignant cells.

Given the inadequacy of single outcome measures such as survival, neurological examination, or cytological examination, many investigators have attempted to use response definitions combining cytological and clinical information. A number of studies have demonstrated improved survival in patients who responded compared with those who did not respond to treatment, where response was defined as various combinations of cytological and 
clinical improvement.[11,36,42,75] Similarly, one trial has evaluated "integrated" measures of quality of life as potentially valuable endpoints in neoplastic meningitis.[35] In this trial, both the functional assessment of cancer therapy-central nervous system (FACT-CNS)[12] and Quality-Adjusted Time Without Symptoms and Toxicity (Q-TWiST) methodology[17,30] were used. Although there was no difference in pre- and posttreatment FACT-CNS scores between the two treatment arms in this study, when responding patients were compared to nonresponders (regardless of treatment arm), responders demonstrated an improved quality of life. A similar and more impressive difference in "TWiST" was seen between responders and nonresponders.

\section{CONCLUSIONS}

A century after the first clinical and pathological recognition of neoplastic meningitis as a disease entity, our ability to diagnose this disease and reliably measure response to treatment is still inadequate. Cerebrospinal fluid cytological examination remains the diagnostic gold standard, but its sensitivity is strongly dependent on a set of operator-controlled test specifications, most of which are now well known but are rarely adhered to.[32,73] In addition, the importance of other test parameters such as communication between clinician and cytopathologist remains unexplored. The role of ancillary CSF markers is also uncertain. Measurement of biochemical markers of tumor growth may provide strong supportive evidence of the presence of neoplastic meningitis. More important, these markers may provide information on prognosis and tumor behavior and may even serve as early indicators of tumor recurrence. Ultimately, this should result in a better understanding of the biology of neoplastic meningitis and thus more astute timing and selection of available therapies. At this time, however, there is insufficient evidence to allow any biochemical or molecular biological marker in the CSF to serve as a diagnostic alternative to CSF cytological examination. Similarly, CSF immunohistochemical techniques dramatically enhance the cytopathologist's ability to identify the tissue of origin of malignant cells in the CSF, but these techniques cannot substitute for conventional CSF cytological examination in establishing the diagnosis of cancer. Neuroimaging studies, in particular MR imaging of the neuraxis, have also been advocated, in combination with the clinical examination, as sufficient for the diagnosis of neoplastic meningitis in the absence of a positive CSF cytology result. Although some studies do show moderate correlation between CSF cytology results and specific MR findings, the use of MR imaging as an alternative to CSF cytological examination presents significant problems. Because no prospective trials or case series have been published in which outcome and other characteristics of patients with MR imaging-defined neoplastic meningitis are examined, it remains unclear whether this group of patients has the same disease as those with positive CSF cytology results. Magnetic resonance imaging abnormalities may identify a subgroup of patients with neoplastic meningitis whose disease behavior, response to treatment, and survival differ from those without MR findings. In addition, because our ability to treat bulky subarachnoid tumor with intrathecal chemotherapy is limited, serial MR imaging may not be helpful in monitoring the success of this type of therapy.

The assessment of treatment outcome in patients with neoplastic meningitis is even less securely defined. Cerebrospinal fluid cytology, even when precisely sampled, is probably inadequate as a single outcome measure. Some patients clearly progress neurologically and die from neoplastic meningitis in the absence of persistent, identifiable malignant cells in the CSF. In part, this may reflect the limitations described for the use of cytology in the diagnosis of neoplastic meningitis. In addition, monitoring of CSF cytology results during therapy is complicated by the possibility of sterilizing only the portion of the subarachnoid space from which the CSF sample is obtained (for example, ventricular CSF when intrathecal chemotherapy is administered through an intraventricular reservoir) and by the presence of treatment-related cytological changes that may mimic or obscure the presence of malignant cells. Finally, because most patients have progressive cancer outside of the CSF, clinical outcome is often independent of the course of disease within the CSF.

The sometimes overriding clinical importance of extra-CSF malignancy in patients with neoplastic meningitis may also degrade the usefulness of clinical measures of response such as the neurological examination, KPS score, and global quality of life measures. Moreover, neoplastic meningitis-related deficits present at the time of diagnosis often fail to resolve despite apparently successful therapy as measured by CSF cytology results, radiographic tumor burden, CSF marker studies, and patient survival. As a result of this lack of resilience of the central nervous system, 
successful therapy usually can do no more than maintain clinical status at the level present when therapy began. Although this provides a strong rationale for early diagnosis and treatment, it complicates the use of clinical response measures for assessing outcome. Despite these shortcomings, some measure of clinical response or quality of life is important, lest treatments be adopted that simply prolong survival at an undesirably low level of function or intolerably high level of suffering.[27,35] Similarly, the relationship of cause of death to neoplastic meningitis is also, potentially, a very useful ancillary outcome measure, if prospectively defined and determined by examiners blinded to treatment status.

Ultimately, the literature permits a few conclusions. As a current diagnostic gold standard, CSF cytological examination, performed in a standardized and rigorous way, seems to be optimum. Additional study of ancillary diagnostic techniques, particularly MR imaging and molecular biological markers of CSF malignancy, should be pursued. As an ideal outcome measure, no single criterion is adequate. A combination of the results of CSF cytological examination and scoring on a standardized neurological examination or measure of performance is probably the best currently available strategy, but substantial room for improvement remains. This combined endpoint should be supplemented by at least three secondary measurements: quality of life, survival, and relation of death to neoplastic meningitis. In the end, the strongest conclusion justified by this literature review is that 100 years of study have yielded relatively few answers and underscore the need for additional well-designed prospective trials focusing on diagnosis and comparing various outcomes, including those of interest to patients who suffer from the disease as well as those who attempt to treat it.

\section{References}

1. Anderson NE, Willoughby EW: Chronic meningitis without predisposing illness--a review of 83 cases. Q J Med 63:283-295, 1987

2. Andrews JM, Schumann GB: Neurocytopathology. Baltimore: Williams \& Wilkins, 1992

3. Bach F, Bjerregaard B, Soletormos G, et al: Diagnostic value of cerebrospinal fluid cytology in comparison with tumor marker activity in central nervous system metastases secondary to breast cancer. Cancer 72:2376-2382, 1993

4. Balm M, Hammack J: Leptomeningeal carcinomatosis: presenting features and prognostic factors. Arch Neurol 53:626-632, 1996

5. Berg SL, Balis FM, Zimm S, et al: Phase I/II trial and pharmacokinetics of intrathecal diaziquone in refractory meningeal malignancies. J Clin Oncol 10:143-148, 1992

6. Bigner DD, Brown M, Coleman RE, et al: Phase I studies of treatment of malignant gliomas and neoplastic meningitis with 131I-radiolabeled monoclonal antibodies anti-tenascin 81C6 and anti-chondroitin proteoglycan sulfate Me1-14 F (ab') $2^{--a}$ preliminary report. J Neurooncol 24:109-122, 1995

7. Bigner SH: Cerebrospinal fluid (CSF) cytology: current status and diagnostic applications. J Neuropathol Exp Neurol 51:235-245, 1992

8. Bigner SH, Johnston WW: Cytopathology of the Central Nervous System. Chicago: American Society of Clinical Pathologists, 1994

9. Bigner SH, Johnston WW: The diagnostic challenge of tumors manifested initially by the shedding of cells into cerebrospinal fluid. Acta Cytol 28:29-36, 1984

10. Bleyer WA, Poplack DG: Intraventricular versus intralumbar methotrexate for central-nervous-system leukemia: prolonged remission with the Ommaya reservoir. Med Pediatr Oncol 6:207-213, 1979

11. Boogerd W, Hart AAM, van der Sande JJ, et al: Meningeal carcinomatosis in breast cancer. Prognostic factors 
and influence of treatment. Cancer 67:1685-1695, 1991

12. Cella DG, Tulsky DS, Gray G, et al: The Functional Assessment of Cancer Therapy scale: development and validation of the general measure. J Clin Oncol 11:570-579, 1993

13. Chamberlain MC, Corey-Bloom J: Leptomeningeal metastases: ${ }^{111}$ indium-DTPA CSF flow studies. Neurology 41:1765-1769, 1991

14. Chamberlain MC, Kormanik P: Carcinoma meningitis secondary to non-small cell lung cancer. Combined modality therapy. Arch Neurol 55:506-512, 1998

15. Chamberlain MC, Sandy AD, Press GA: Leptomeningeal metastasis: a comparison of gadolinium-enhanced MR and contrast-enhanced CT of the brain. Neurology 40:435-438, 1990

16. Cibas ES, Malkin MG, Posner JB, et al: Detection of DNA abnormalities by flow cytometry in cells from cerebrospinal fluid. Am J Clin Pathol 88:570-577, 1987

17. Cole BF, Gelber RD, Kirkwood JM, et al: Quality-of-life-adjusted survival analysis of interferon alfa-2b adjuvant treatment of high-risk resected cutaneous melanoma: an Eastern Cooperative Oncology Group study. J Clin Oncol 14:2666-2673, 1996

18. de Visser BWO, Somers R, Nooyen WH, et al: Intraventricular methotrexate therapy of leptomeningeal metastasis from breast carcinoma. Neurology 33:1565-1572, 1983

19. Dux R, Kindler-Rohrborn A, Annas M, et al: A standardized protocol for flow cytometric analysis of cells isolated from cerebrospinal fluid. J Neurol Sci 121:74-78, 1994

20. Eberth CJ: Zur Entwicklung des Epithelioms (Cholesteatoms) der Pia und der Lunge. Virchows Arch Pathol Anat 49:51-63, 1870

21. Edwards MS, Levin VA, Seager ML, et al: Intrathecal chemotherapy for leptomeningeal dissemination of medulloblastoma. Childs Brain 8:444-451, 1981

22. Fishman RA: Cerebrospinal Fluid in Diseases of the Nervous System, ed 2. Philadelphia: WB Saunders, 1992

23. Fizazi K, Asselain B, Vincent-Salomon A, et al: Meningeal carcinomatosis in patients with breast carcinoma. Clinical features, prognostic factors, and results of a high-dose intrathecal methotrexate regimen. Cancer 77:1315-1323, 1996

24. Forman AD: Diagnosis of malignant meningitis. Ann Neurol 39:413, 1996 (Letter)

25. Freilich RJ, Krol G, DeAngelis LM: Neuroimaging and cerebrospinal fluid cytology in the diagnosis of leptomeningeal metastasis. Ann Neurol 38:51-57, 1995

26. Friedberg MH, Glantz MJ, Klempner MS, et al: Specific matrix metalloproteinase profiles in the cerebrospinal fluid correlate with the presence of malignant astrocytomas, brain metastases, and carcinomatous meningitis.

Cancer 82:923-930, 1998

27. Fries JF: Aging, natural death, and the compression of morbidity. N Engl J Med 303:130-135, 1980

28. Fukui MB, Meltzer CC, Kanal E, et al: MR imaging of the meninges. Part II. Neoplastic disease. Radiology 201:605-612, 1996

29. Fulton DS, Levin VA, Gutin PH, et al: Intrathecal cytosine arabinoside for the treatment of meningeal metastases from malignant brain tumors and systemic tumors. Cancer Chemother Pharmacol 8:285-291, 1982 
30. Gelber RD, Goldhirsch A, Cole BF, et al: A quality-adjusted time without symptoms or toxicity (Q-TWiST) analysis of adjuvant radiation therapy and chemotherapy for resectable rectal cancer. J Natl Cancer Inst 88:1039-1045, 1996

31. Giannone L, Greco FA, Hainsworth JD: Combination intraventricular chemotherapy for meningeal neoplasia. J Clin Oncol 4:68-73, 1986

32. Glantz MJ, Cole BF, Glantz LK, et al: Cerebrospinal fluid cytology in patients with cancer. Minimizing false-negative results. Cancer 82:733-739, 1998

33. Glantz MJ, Cole BF, Recht L, et al: High-dose intravenous methotrexate for patients with nonleukemic leptomeningeal cancer: is intrathecal chemotherapy necessary? J Clin Oncol 16:1561-1567, 1998

34. Glantz MJ, Hall WA, Cole BF, et al: Diagnosis, management, and survival of patients with leptomeningeal cancer based on cerebrospinal fluid-flow studies. Cancer 75:2919-2931, 1995

35. Glantz MJ, Kim L: Factoring the whole patient into the whole tumor volume. Am Coll Radiat Oncol Bull 5:8-10, 1998

36. Glantz MJ, Phuphanich S, White CA, et al: Treatment of leptomeningeal metastases with intra-CSF depofoam encapsulated cytarabine. Proc Am Soc Clin Oncol 15:377, 1996

37. Glass JP, Melamed M, Chernik NL, et al: Malignant cells in cerebrospinal fluid (CSF): the meaning of a positive CSF cytology. Neurology 29:1369-1375, 1979

38. Grant R, Naylor B, Greenberg HS, et al: Clinical outcome in aggressively treated meningeal carcinomatosis. Arch Neurol 51:457-461, 1994

39. Grossman S, Moynihan T: Neurologic complications of systemic cancer: neoplastic meningitis. Neurol Clin 9:843-856, 1991

40. Grossman SA, Finkelstein DM, Ruckdeschel JC, et al: Randomized prospective comparison of intraventricular methotrexate and thiotepa in patients with previously untreated neoplastic meningitis. J Clin Oncol 11:561-569, 1993

41. Grossman SA, Trump DL, Chen DCP, et al: Cerebrospinal fluid flow abnormalities in patients with neoplastic meningitis: An evaluation using 111 indium-DTPA ventriculography. Am J Med 73:641-647, 1982

42. Hitchins RN, Bell DR, Woods RL, et al: A prospective randomized trial of single-agent versus combination chemotherapy in meningeal carcinomatosis. J Clin Oncol 5:1655-1662, 1987

43. Hovestadt A, Henzen-Logmans SC, Vecht CJ: Immunohistochemical analysis of the cerebrospinal fluid for carcinomatous and lymphomatous leptomeningitis. Br J Cancer 62:653-654, 1990

44. Hsu S, Cole B, Recht L, et al: Frequency and prognostic significance of a positive cerebrospinal fluid cytology in patients with gliomas. Neurology 48:A35, 1997 (Abstract)

45. Jaeckle KA: Assessment of tumor markers in cerebrospinal fluid. Clin Lab Med 5:303-315, 1985

46. Jayson GC, Howell A, Harris M, et al: Carcinomatous meningitis in patients with breast cancer. An aggressive disease variant. Cancer 74:3135-3141, 1994

47. Kaplan JG, DeSouza TG, Farkash A, et al: Leptomeningeal metastases: comparison of clinical features and laboratory data of solid tumors, lymphomas and leukemias. J Neurooncol 9:225-229, 1990

48. Kioumehr F, Dadsetan MR, Feldman N, et al: Postcontrast MRI of cranial meninges: leptomeningitis versus pachymeningitis. J Comput Assist Tomogr 19:713-720, 1995 
49. Koskiniemi M: Malignancy markers in the cerebrospinal fluid. Eur J Pediatr 148:3-8, 1988

50. MacKenzie JM: Malignant meningitis: a rational approach to cerebrospinal fluid cytology. J Clin Pathol 49:497-499, 1996

51. Marks V, Marrack D: Tumour cells in the cerebrospinal fluid. J Neurol Neurosurg Psychiatry 23:194-201, 1960

52. Moriarty AT, Wiersema L, Snyder W, et al: Immunophenotyping of cytologic specimens by flow cytometry. Diagn Cytopathol 9:252-258, 1993

53. Nakagawa H, Murasawa A, Kubo S, et al: Diagnosis and treatment of patients with meningeal carcinomatosis. J Neurooncol 13:81-89, 1992

54. Newton HB, Fleisher M, Schwartz MK, et al: Glucosephosphate isomerase as a CSF marker for leptomeningeal metastasis. Neurology 41:395-398, 1991

55. Pannullo SC, Reich JB, Krol G, et al: MRI changes in intracranial hypotension. Neurology 43:919-926, 1993

56. Pfeffer MR, Wygoda M, Siegal T: Leptomeningeal metastases--treatment results in 98 consecutive patients. Isr J Med Sci 24:611-618, 1988

57. Posner JB: Neurologic Complications of Cancer. Philadelphia: FA Davis, 1995

58. River Y, Schwartz A, Gomori JM, et al: Clinical significance of diffuse dural enhancement detected by magnetic resonance imaging. J Neurosurg 85:777-783, 1996

59. Rhodes CH, Glantz MJ, Glantz L, et al: A comparison of polymerase chain reaction examination of cerebrospinal fluid and conventional cytology in the diagnosis of lymphomatous meningitis. Cancer 77:543-548, 1996

60. Rhodes CH, Honsinger C, Sorenson GD: PCR-detection of tumor-derived p53 DNA in cerebrospinal fluid. Am J Clin Pathol

61. Rosen ST, Aisner J, Makuch RW, et al: Carcinomatous leptomeningitis in small cell lung cancer: a clinicopathologic review of the national cancer institute experience. Am J Med 61:45-53, 1982

62. Saenger A: Ueber Hirnsymptome bei Carcinomatose. Munchen Med Wchnschr 49:826, 1901

63. Sause WT, Crowley J, Eyre HJ, et al: Whole brain irradiation and intrathecal methotrexate in the treatment of solid tumor leptomeningeal metastases--a Southwest Oncology Group study. J Neurooncol 6:107-112, 1988

64. Schold SC, Wasserstrom WR, Fleisher M, et al: Cerebrospinal fluid biochemical markers of central nervous system metastases. Ann Neurol 8:597-604, 1980

65. Schumacher DJ, Tien RD, Friedman H: Gadolinium enhancement of the leptomeninges caused by hydrocephalus: a potential mimic of leptomeningeal metastases. AJNR 15:639-641, 1994

66. Siegal T, Lossos A, Pfeffer MR: Leptomeningeal metastases: analysis of 31 patients with sustained off-therapy response following combined-modality therapy. Neurology 4:1463-1469, 1994

67. Stewart DJ, Maroun JA, Hugenholtz H, et al: Combined intraommaya methotrexate, cytosine arabinoside, hydrocortisone and thio-TEPA for meningeal involvement by malignancies. J Neurooncol 5:315-322, 1987

68. Sze G, Soletsky S, Bronen R: MR imaging of the cranial meninges with emphasis on contrast enhancement and meningeal carcinomatosis. AJNR 10:965-975, 1989 
69. Theodore WH, Gendelman S: Meningeal carcinomatosis. Arch Neurol 38:696-699, 1981

70. Trump DL, Grossman SA, Thompson G, et al: Treatment of neoplastic meningitis with intraventricular thiotepa and methotrexate. Cancer Treat Rep 66:1549-1551, 1982

71. van Zanten AP, Twijnstra A, Ongerboer de Visser BW, et al: Cerebrospinal fluid tumour markers in patients treated for meningeal malignancy. J Neurol Neurosurg Psychiatry 54:119-123, 1991

72. Vick WW, Wikstrand CJ, Bullard DE, et al: The use of a panel of monoclonal antibodies in the evaluation of cytologic specimens from the central nervous system. Acta Cytol 31:815-824, 1987

73. Walts AE, Strigle S: Toward optimal use of the cytology laboratory: quality improvement and cerebrospinal fluid specimens. Diagn Cytopathol 13:357-361, 1995

74. Wasserstrom WR, Glass JP, Posner JB: Diagnosis and treatment of leptomeningeal metastases from solid tumors: experience with 90 patients. Cancer 49:759-772, 1982

75. Yap HY, Yap BS, Rasmussen S, et al: Treatment for meningeal carcinomatosis in breast cancer. Cancer 50:219-222, 1982

76. Yap HY, Yap BS, Tashima CK, et al: Meningeal carcinomatosis in breast cancer. Cancer 42:283-286, 1978

77. Yousem D, Patrone PM, Grossman R: Leptomeningeal metastases: MR evaluation. J Comput Assist Tomogr 14:255-261, 1990

Manuscript received April 23, 1998.

Accepted in final form May 20, 1998.

Address reprint requests to: Michael Glantz, M.D., University of Massachusetts School of Public Health, Arnold House, Box 30430, Amherst, Massachusetts 01003-0430. email: MJG@MASSMED.ORG. 